\title{
COVID-19 Total Mortality and Relative Waves: the Reasons for the Differences among European Countries
}

\author{
U. Cornelli, M. Recchia, G. Belcaro
}

\section{ABSTRACT}

Background: Several mortality waves (between 1 to 5 ) have been observed over time in the 47 European countries.

Material and Methods: The data on mortality rate shown on the WHO dashboard were used, and twelve LEEDELS variables (life expectancy, ecological, economic, demographic and lifestyle) during the period between March 2020 and September 2021. WMVs (weighted median values) were used to calculate the mortality rates and their respective waves. The partition model was used to identify which LEEDELS variables correlated with the mortality rates (predictors).

Results: In the partition model four LEEDELS predictors were considered relevant: number of cars per $10^{3}$ inhabitants, GDP, percentage of population over 65 years old, and life expectancy. The remaining eight LEEDELS variables (total population aged over 65 years old, population density, urban population, education expenditure, number of hospital beds, particulate matter, number of mobile phones, and number of internet connections) were irrelevant. The analysis revealed four pathways (from P1 to $P 4)$, which limit or increase the WMVs respectively. The $P 3$ pathway was shown to be at the highest risk of death while P1 was more protective.

Conclusions: High GDP, a high percentage of the population over 65 years of age and life expectancy are crucial for WMV containment, represented by $P 1$. The pathway P3, characterized by high GDP, low percentage of population over 65 is at higher risk. Population density, particulate matter, number of hospital beds and expenditure on education, cell phone $x 1^{3}$ inhabitants were not found to be causal variables.

Keywords: COVID-19; demography, ecology, economy, life expectancy, lifestyle.

\section{INTRODUCTION}

The COVID-19 pandemic has occurred as a succession of waves in all countries around the world.

The pattern does not seem to be linked to seasons and is similar in all European and non-European countries.

The causes of this wave-like behavior in mortality rate are unknown, and they have continued to occur even after the start of vaccination programmes. Use of the various vaccines available has clearly contributed to reducing mortality, to such an extent that it is believed to be essential to continue their administration for some time.

However, besides the vaccination campaign, the conditions of a given country in terms of LEEDELS variables (life expectancy, ecological, economic, demographic and lifestyle) are believed to be important in determining the size of the mortality rate and its trend.

It has already been noted that, in some countries (e.g. Italy) [1], the most affected regions are the most prosperous ones, which seems to be at odds with their greater ability to react
Submitted : November 25, 2021

Published : February 23, 2022

ISSN: $2593-8339$

DOI: $10.24018 /$ ejmed.2022.4.1.1155

\section{U. Cornelli*}

Loyola University School of Medicine, Chicago, USA.

(e-mail: ucornelli@gmail.com)

M. Recchia

StatMed, Milano, Italy.

(e-mail: statmed@hotmail.com)

G. Belcaro

University G. d'Annunzio, Pescara,

Chieti, Italy.

(e-mail: cardres@abol.it)

*Corresponding Author on the basis of the availability of resources. If we consider the world data for $193 \mathrm{WHO}$ countries, we can see five waves in weekly mortality rate during the period from March to September (Fig. 1). Fig. 2 shows the data for 47 European countries, excluding Russia.

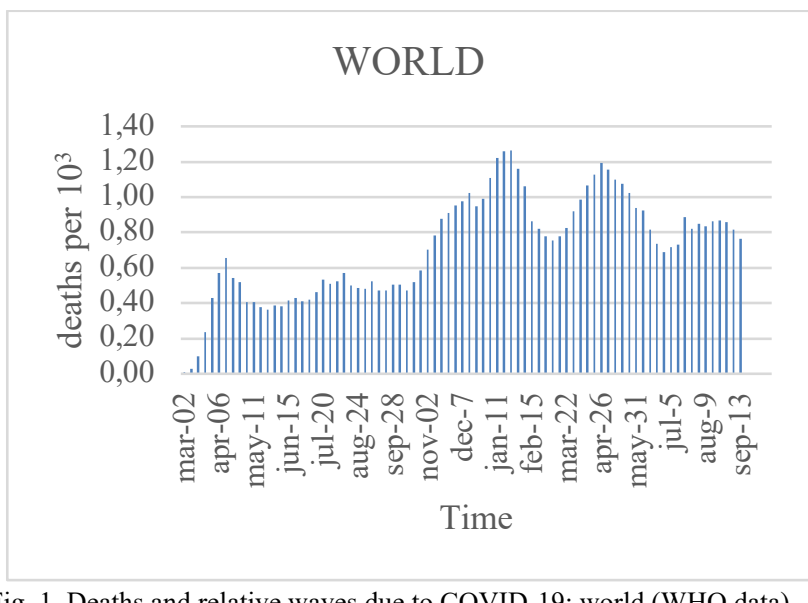

Fig. 1. Deaths and relative waves due to COVID-19: world (WHO data). 


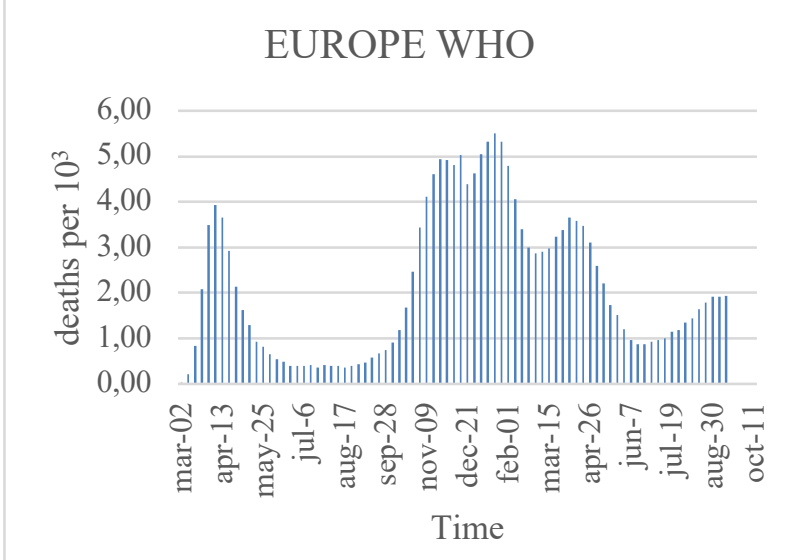

Fig. 2. Deaths and relative waves due to COVID-19: 47 European countries, excluding Russia (WHO data).

In this case, applying the same criteria, there are four waves and the mortality rate is significantly higher than the world average. However, there are very substantial differences among the various European countries. To illustrate this, Fig. 3 shows the data from Slovakia and Fig. 4, from Turkey.

A clear difference in the trend in mortality rates is evident from these examples.

The aim of this research is to attempt to correlate the trends in mortality rates - in terms of total number of cases and waves - with LEEDELS variables (life expectancy, ecological, economic, demographic and lifestyle) in order to identify any predictors that may have conditioned these events.

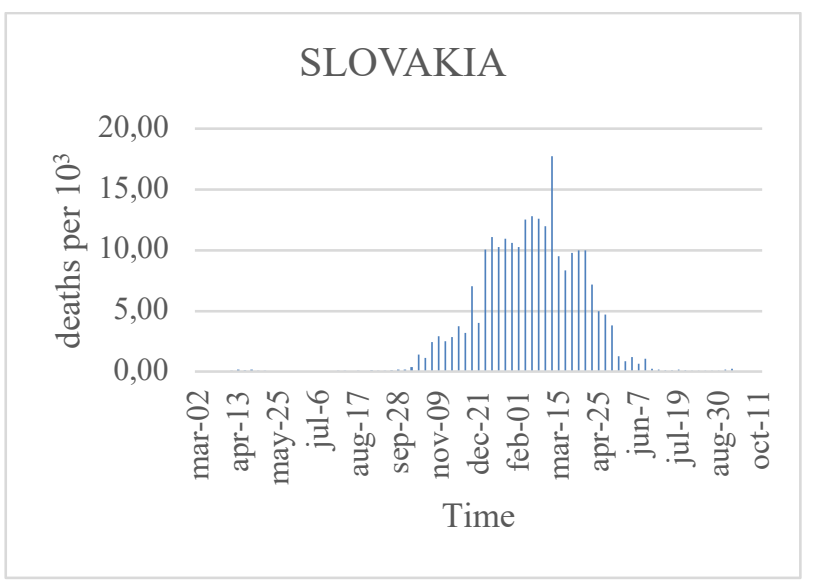

Fig. 3. Deaths and relative waves due to COVID-19: Slovakia.

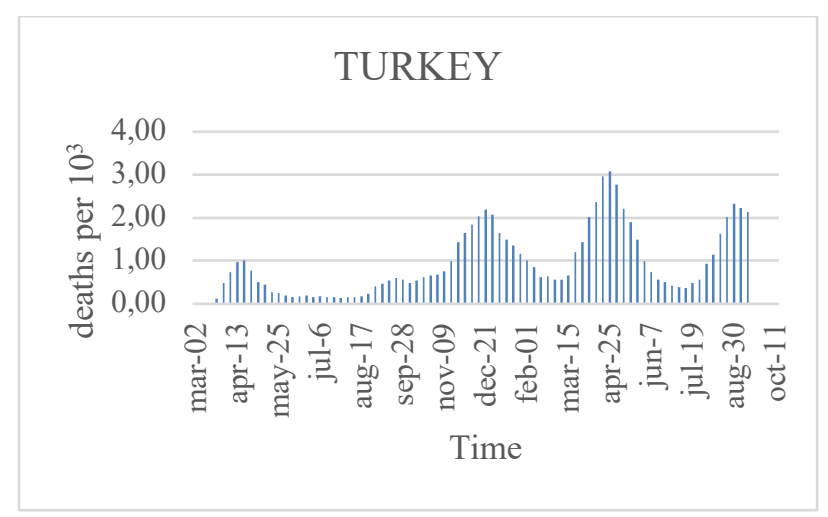

Fig. 4. Deaths and relative waves due to COVID-19: Turkey.

\section{MATERIAL AND MethodS}

Weekly mortality data (presumably) due to COVID-19 infections were collected from the WHO Dashboard [2].

Only twelve LEEDELS variables were considered, taken from the [3], [4].

These variables were life expectancy, total population over 65 years old, percentage population over 65 years old, population density, percentage of urban population, GDP, percentage of GDP devoted to health expenditure, percentage of GDP devoted to education expenditure, particulate matter (PM), and the number of cars, mobile phones and internet connections per $10^{3}$ inhabitants.

\section{Statistical Methods}

The median mortality rates for the period concerned (March 2020 -September 2021) were calculated for the countries considered in this study, and mortality cycles were inferred after the curves were smoothed using a nonparametric density estimation method (kernel density estimation). The next steps in the statistical analysis were:

- Calculation of the weighted median mortality rates (median per number of cycles), hereafter referred to as WMVs (weighted median values), for each country.

- Analysis of WMV distribution and the arbitrary creation of four class intervals $(0-80,81-310,311-376$ and over 376).

- Launch of the partition algorithm with a set of $47 \mathrm{WMVs}$ on a dependent variable $\mathrm{Y}(0-80,81-310,311-376$ and over 376 ) and the various potential explanatory variables $\mathrm{X}$ (twelve LEEDELS variables or predictors).

The partition algorithm considers WMVs recursively according to the relationship between the predictors and creates a decision tree. Using the partition algorithm, we can find the best possible split between predictors to predict the response. The data partitions were calculated recursively to form a tree of decision rules. Partition was continued until the required fit was achieved, which consisted of the largest number of possible splits.

We arbitrarily chose four levels at which to stop partition in order to obtain clusters containing an acceptable number of countries (at least five).

In other words, once the target variable (the four WMV categories) was fixed and the twelve LEEDELS variables were defined as possible predictors, four partition levels were arbitrarily chosen to find which subsets of predictors significantly altered the probability of the WMVs.

Average values were calculated for some variables and the significance of the comparisons was calculated using the Mann-Whitney U test.

All statistical data evaluation was performed using JMP14 Pro software (SAS Institute). 
TABLE I: TOTAL COVID-19 MORTALITY RATE PER 103 INHABITANTS, RELATIVE WAVES, AND WMVS IN 47 EUROPEAN COUNTRIES AND SOME OF THE WORLD'S MOST HIGHLY POPULATED REGIONS

\begin{tabular}{|c|c|c|c|c|c|c|c|}
\hline Country & Mortality rate per $10^{3}$ & Waves & WMV & Country & Mortality rate per $10^{3}$ & Waves & WMV \\
\hline Albania & 0.897 & 5 & $81-310$ & Liechtenstein & 1.481 & 1 & $0-80$ \\
\hline Andorra & 1.621 & 3 & $0-80$ & Lithuania & 1.631 & 4 & $0-80$ \\
\hline Armenia & 1.718 & 4 & $81-310$ & Luxembourg & 1.510 & 3 & $0-80$ \\
\hline Austria & 1.244 & 4 & $81-310$ & Malta & 1.079 & 4 & $0-80$ \\
\hline Azerbaijan & 0.640 & 4 & $81-310$ & Moldova & 2.225 & 4 & $81-310$ \\
\hline Belgium & 2.256 & 3 & $311-376$ & Monaco & 0.846 & 1 & $0-80$ \\
\hline Bosnia & 2.669 & 5 & $81-310$ & Montenegro & 2.970 & 4 & $0-80$ \\
\hline Bulgaria & 2.855 & 4 & $81-310$ & The Netherlands & 1.078 & 3 & $311-376$ \\
\hline Croatia & 1.974 & 4 & $0-80$ & North Macedonia & 3.102 & 4 & $81-310$ \\
\hline Czechia & 2.863 & 4 & $81-310$ & Norway & 0.162 & 4 & $0-80$ \\
\hline Cyprus & 0.447 & 4 & $0-80$ & Poland & 1.943 & 3 & $311-376$ \\
\hline Denmark & 0.464 & 3 & $0-80$ & Portugal & 1.742 & 4 & $81-310$ \\
\hline Estonia & 1.008 & 4 & $0-80$ & Romania & 1.586 & 5 & $>376$ \\
\hline Finland & 0.183 & 3 & $0-80$ & San Marino & 2.670 & 2 & $0-80$ \\
\hline France & 1.778 & 5 & $>376$ & Serbia & 1.097 & 5 & $81-310$ \\
\hline Georgia & 2.297 & 3 & $81-310$ & Slovakia & 2.381 & 2 & $0-80$ \\
\hline Germany & 1.153 & 4. & $>376$ & Slovenia & 2.198 & 4 & $0-80$ \\
\hline Greece & 1.331 & 4 & $81-310$ & Spain & 1.575 & 4 & $>376$ \\
\hline Hungary & 3.041 & 4 & $81-310$ & Sweden & 1.414 & 3 & $81-310$ \\
\hline Iceland & 0.095 & 2 & $0-80$ & Switzerland & 1.196 & 3 & $0-80$ \\
\hline Ireland & 1.120 & 3 & $0-80$ & Turkey & 0.758 & 4 & $311-376$ \\
\hline Italy & 2.143 & 4 & $>376$ & Ukraine & 1.299 & 3 & $311-376$ \\
\hline Kosovo & 1.582 & 5 & $81-310$ & United Kingdom & 2.092 & 4 & $>376$ \\
\hline Latvia & 1.319 & 3 & $0-80$ & Europe & 1.743 & 5 & $81-310$ \\
\hline The USA & 2.079 & 4 & $>376$ & Russia & 1.347 & 4 & $>376$ \\
\hline Mexico & 2.190 & 3 & $>376$ & Brazil & 2.818 & 2 & $>376$ \\
\hline China & 0.020 & 2 & $0-80$ & India & 0.322 & 2 & $0-80$ \\
\hline Africa & 0.115 & 3 & $0-80$ & World & 0.580 & 5 & $0-80$ \\
\hline
\end{tabular}

TABLE II: DISCRIMINATING POWERS OF THE TWELVE LEEDELS VARIABLES

\begin{tabular}{cccc}
\hline \hline Predictor & Discriminating power & Predictor & Discriminating power \\
\hline \hline Cars per $10^{3}$ & 0.3731 & \% urban population & 0 \\
GDP & 0.2265 & Education expenditure /GDP & 0 \\
Life expectancy & 0.2034 & Hospital beds per $10^{3}$ inhabitants & 0 \\
$\%>65$ years & 0.1970 & Particulate matter (PM) & 0 \\
$>65$ years & 0 & Mobile phones per $10^{3}$ inhabitants & 0 \\
Urban density $(\%)$ & 0 & Internet connections per $10^{3}$ inhabitants & 0 \\
\hline \hline
\end{tabular}

\section{RESULTS}

Table I shows the mortality per $10^{3}$ inhabitants, the number of respective peaks and the WMV interval.

WMVs ranged from 0.16 to over $376 / 10^{3}$ inhabitants.

We analyzed the twelve LEEDELS variables (predictors) in relation to the WMVs using the partition algorithm model. This allowed us to identify the most powerful predictors (Table II). Only four variables were found to have a determining weight.

The first predictor was the number of cars per $10^{3}$ inhabitants, which was seen to have the highest discriminating power when the cut-off was set at $505 / 10^{3}$ inhabitants.

The second predictor was GDP, with a cut-off of $€ 7376 /$ year. The third was the percentage of subjects aged over 65 , with a cut-off of $32.5 \%$. The fourth was life expectancy, which was capped at 82 .

Fig. 5 shows the partition algorithm.

Number of cars greater than 505 per $10^{3}$ inhabitants is the sole predictor for nineteen countries. They have a higher WMV 0-80 interval probability than the 47 countries taken together, 0.7713 and 0.4255 respectively.

For the remaining 28 countries, all four predictors are found and follow a similar path which ends in two different ways: life expectancy $<82.17$ (pathway 1 or P1) and life expectancy $\geq 82.17$ (pathway 2 or $\mathrm{P} 2$ ).

$\mathrm{P} 1$ is preferable, since the $0-80 \mathrm{WMV}$ interval has a probability of 0.6737 , which is much higher than the probability of 0.4255 for all 47 countries together.

On the contrary, P2 is much less preferable, since the $0-80$ WMV interval falls from a probability of 0.4255 to one of 0.0556 .

In some countries (5), on the other hand, only three predictors are found, which however do not increase the 0-80 WMV interval probability. Instead, they reduce it to 0.0650 and increase the $>376$ up to 0.6940 .

These countries fit the model P3 which is consistent with the higher risk of mortality.

In some other countries (10) two predictors only were found, cars $<505$ and GDP $<7647$ which follow the pathway $\mathrm{P} 4$, characterized by a reduction of WMV from 0.4255 to 0.0365 and can be considered at high risk.

In predictive terms, a country characterized by fewer than 505 cars per $10^{3}$ inhabitants, GDP $\geq 7476$ USD/inhabitant, population with percentage of people aged over 65 years $\geq$ 32.5 and life expectancy $<82.17$ years will be in a better condition in terms of mortality rate (P1). 
On the contrary, a country characterized by fewer than 505 cars per $10^{3}$ inhabitants, GDP $\geq 7467$ USD/inhabitant, population with percentage of people aged over 65 years $\geq$ 32.5 and life expectancy $\geq 82.17$ will be in a less favorable condition in terms of mortality rate (P2).

Lastly, the variable that discriminates between P1 and P2 is life expectancy. The lower it is, the more favorable conditions are in terms of COVID-19 mortality rate.

The mortality rate per $10^{3}$ inhabitants and the number of relative waves was analyzed separately without applying the WMVs in 24 Eastern European countries in comparison with 23 other European countries. The means of the values were $3.1 \pm 0.97$ and $4.0 \pm 0.73$ respectively (Mann-Whitney $\mathrm{U}$ test $\mathrm{p}<0.05)$.

Similarly, the mean number of deaths is higher in Eastern European countries than in other European countries, $1.892 \pm$
0.7702 and $1.276 \pm 0.6492$ per $10^{3}$ inhabitants respectively (Mann-Whitney U test $\mathrm{p}<0.05$ ).

Applying the WMV calculation method, the values in the 0-80 and 81-310 intervals in the two blocks of countries were 7 and 13 respectively for the Eastern European countries, whereas in the other European countries they were 13 and 3 respectively. This suggest that Eastern European countries are more fragile.

The average number of cars per $10^{3}$ inhabitants, GDP, percentage of people aged over 65 in Eastern European countries are lower than in the rest of Europe (Mann-Whitney $U$ test $p<0.05)$, thus confirming the good predictive ability of our model.

In short, Eastern European countries fit best with P3 (i.e. the higher risk model).

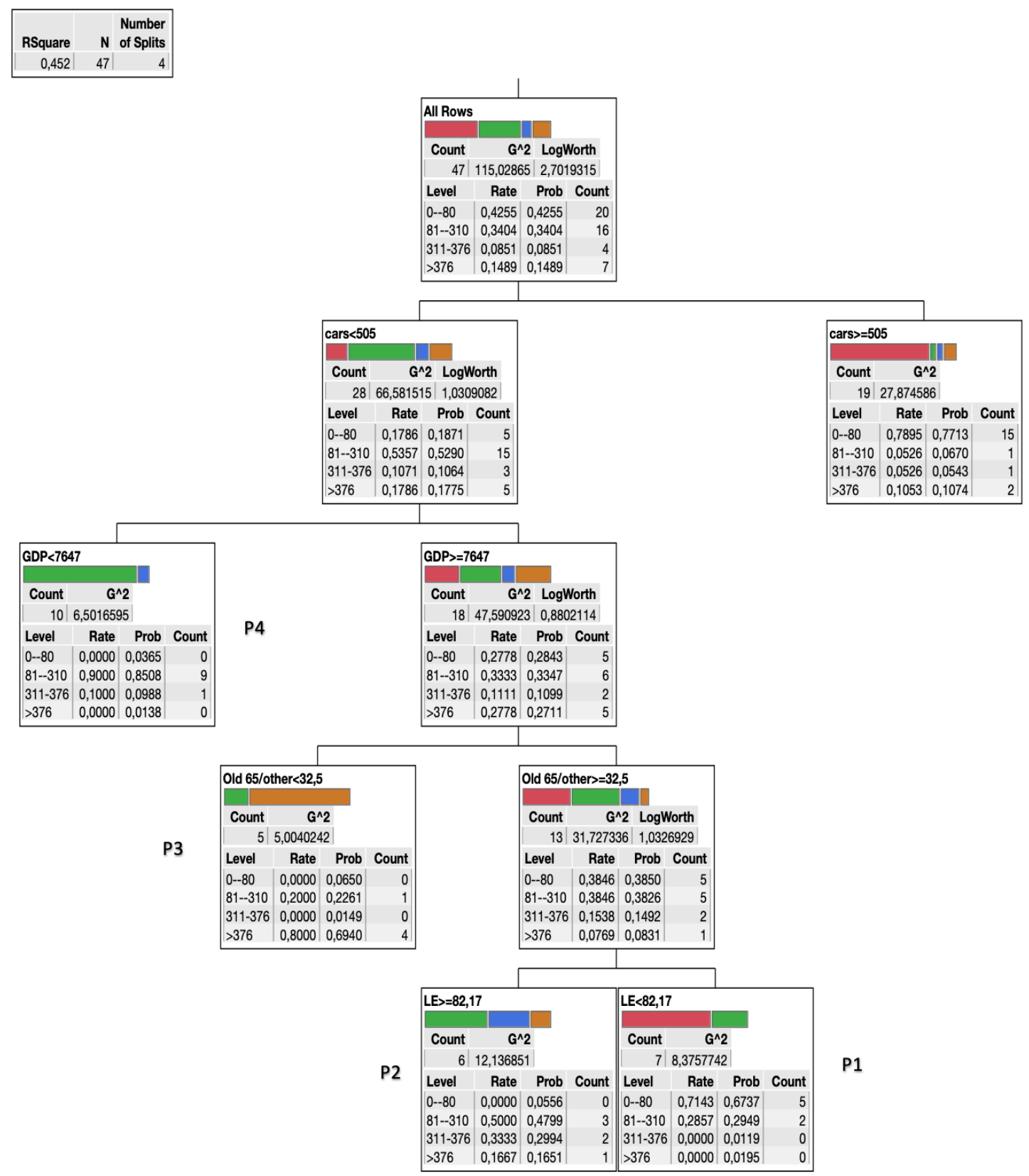

Fig. 5. Each box shows the four WMV levels and their incidence on the four predictors. The first box shows the total number of countries (47) broken down by WMV level (e.g. between 0-80 in twenty countries and over 376 in seven countries). All the other boxes refer to individual predictors with their WMVs (level), their frequency (rate), their incidence (prob) and the number of countries with that particular characteristic (count); P1 = pathway $1 ; \mathrm{P} 2=$ pathway 2 ; $\mathrm{P} 3=$ pathway $3 ; \mathrm{P} 4=$ pathway 4 . The model can be considered reliable because $\mathrm{r}^{2}=0.452$. 


\section{DISCUSSION}

We attempted to justify the differences in mortality rate trends in different countries, both in terms of total numbers and successive waves, by comparing them with LEEDELS variables. Four of these variables were seen to be predictive: number of cars per $10^{3}$ inhabitants, GDP, percentage of people aged over 65, and life expectancy. On the basis of these predictors, the partition algorithm revealed two different "pathways" with different risk levels (P1 and P2). The LEEDELS characteristics of each European country may therefore determine the extent of COVID-19 risk.

Surprisingly, variables such as population density, PM, education expenditure, and number of hospital beds, mobile phones and internet connections proved to be irrelevant.

However, some of these variables have limitations which may affect the results.

In particular GDP (found to be determinant) and PM (found to be irrelevant) illustrate these limitations.

In practice, GDP should be supplemented with information about its use.

In other words, its use to buy cars, for education, for hospital beds, for mobile phones or for internet connections only accounts for part of its use.

In previous research, military expenditure was also considered. It was found to be inversely proportional to the number of vaccine doses administered [5] and thus the consequent protection from COVID-19.

Kind of PM (found to be irrelevant) should also be considered; we should distinguish between natural PM (e.g. desert sand) and industrial pollution.

Even though there are no deserts in Europe, industrial pollution is widespread and of very different kinds. It is not only caused by coal-fired power stations and the iron and steel industry, but principally by livestock farms and the numerous small factories.

Suffice it to say that during the lockdowns, the water in many European rivers almost became clean again.

One further limitation stem from the partition algorithm model, which is normally used on large numbers. Therefore, since the current sample is limited to only 47 countries, its reliability must be treated with caution, even though it is significant.

Despite these limitations, our research has yielded some insights which may be useful.

The pandemic has had dramatic effects and so far resulted in over five million deaths, over one million of which are in Europe.

There were over 170 deaths per $10^{3}$ inhabitants in Europe during the period considered.

Although figures vary considerably from country to country, Europe as a whole has paid a much higher price than much of the rest of the world, where there have been around 58 deaths for every $10^{3}$ inhabitants.

There are also other large countries/regions with mortality rates higher than in Europe, such as the USA, Brazil, and Mexico, where figures far exceed 200 deaths per $10^{3}$ inhabitants.

It is surprising that the USA, which is perhaps the most advanced country in the world, should find itself among the most badly affected by the pandemic.
Another even more surprising figure regards China. There is no doubt whatsoever that COVID-19 originated there. However, it has seen mortality rates which 1-2 orders of magnitude are lower than in the rest of the world.

The partition model suggests that GDP and number of cars per $10^{3}$ inhabitants are two of the four determining variables for the mortality rate in Europe and its trend.

GDP is a direct index of prosperity, while cars are an indirect index of mobility. The hypothesis is that high prosperity and low mobility could be two keys to reduce mortality.

It should be borne in mind that the WMV reflects not only the number of deaths but also the successive waves, whose nature needs some clarification.

The hypothesis is that in the pursuit of profit you "accept the risk" of interpersonal relationships (hence contagion).

The wave represents the extent of the risk and only when it increases substantially does it lead to a consequent reduction in the number of interpersonal contacts needed to produce profit, which then leads to the falling phase of the wave.

This hypothesis is confirmed when we analyze the mortality rate and number of waves in Eastern European countries separately in comparison with other European nations. There are significant differences between the two blocks: mortality rate and number of waves are both higher in Eastern European countries, which mostly fit the P2 model.

Overall, the pursuit of profit for contingent needs is much more pressing in Eastern Europe than in the rest of the economically stronger European countries. Therefore, the respective populations are more likely to accept the risk of infection, which emerges as a greater number of successive waves.

We should also not overlook political/social aspects.

When restrictions become an obligation (e.g. in China), mortality rate and the relative waves are minimized. This was brought about by the country's coercive policy, which is highly punitive and strongly limits individual freedom in a way European countries do not.

Limitations of individual freedom in European countries have caused many social problems, as can be seen from the existence of anti-vaccination (no-vax) and anti-COVID certificate (no-green-pass) movements, which oppose all such policies.

Returning to our model, age-related variables (percentage of subjects aged over 65 and life expectancy) were found to be discriminating. Old age has often been cited as being associated with chronic diseases, which are considered a risk factor in COVID-19 mortality. However, it is known that elderly people tend to die more often than the young, while on the other hand - appropriate chronic treatment has often been found to be protective (e.g. against diabetes) [6]. To some extent, this justifies the fact that a high percentage of inhabitants over 65 years emerges as protective since these people are more frequently treated for chronic diseases.

On the whole, our model based on WMVs revealed two determining aspects: profit and age of the population. When GDP is high and the population has a large number of elderly people, the risk of death is lower provided that the life expectancy will be $<82$ years. In the end, the last discriminant between the model P1 (favorable) and P2 (unfavorable) seems to be the life expectancy. 
In those countries where it is $\geq 82.17$ the risk of COVID19 mortality is higher since the virus make them more fragile. The protection of the chronic therapy in these cases should be more appropriately monitored.

All other LEEDELS variables seem to be irrelevant or at least not very important.

In this discussion, we cannot overlook the public information provided through the media, which has been confusing and conflicting. Even recognizing the important role, the media has played in trying to understand the pandemic, this attempt has in reality done nothing but encourage the public to follow its own path, since there has always been someone authoritative who has told deniers and minimalizers that they are right.

However, the most inexplicable fact is that no authority (e.g. media, virologists and epidemiologists) has given the most obvious piece of advice: COVID-19 is mainly transmitted through saliva and the use of a simple antiseptic mouthwash could (and can) greatly limit the number of infections and subsequent number of deaths.

\section{CONCLUSION}

The mortality rate and its respective waves seem to depend mainly on four determinants, two related to prosperity (number of cars per inhabitant and GDP), and two related to old age.

Not surprisingly, the tragic number of deaths can also be attributed to misinformation exacerbated by many experts in the field, as well as by the media.

\section{AUTHOR CONTRIBUTIONS}

Cornelli U conceived the trial, retrieved some of the WHO data and wrote the article; Belcaro $\mathrm{G}$ retrieved part of the WHO data; Martino Recchia was responsible for the statistical analysis.

All the authors read and approved the final manuscript.

\section{FUNDING}

No funding was requested or received by the authors

\section{CONFLICT OF INTEREST}

Authors declare that they do not have any conflict of interest.

\section{REFERENCES}

[1] Cornelli U, Belcaro G, Cesarone MR, Cotellese R. Coronavirus Cov19: the status in Italy taken as an example of the virus spreading in the world. J Med Clin Res Rev. 2020; 4(4): 1.

[2] World Health Organization. Worldwide Dashboard. 2021.

[3] Atlante Geografico De Agostini 2020 Deluxe Edition. DeA Planeta Books. 2021.

[4] Central Intelligence Agency. The CIA world factbook 2020-2021. Skyhorse Publishing, New York, USA, 2021.

[5] Cornelli U. The delta variant: the choice between spreading vaccines or guns. J Bacter Parasit. 2021; 12: 1-8.

[6] Cornelli U. Diabetes type II and Covid-19: need of rethinking. Curr Res Diab Obesity Journal. 2021; 14(1): 1-2. 